\title{
SAGES remembers Jim Lind
}

\author{
Thomas L. Dent
}

Published online: 13 October 2011

(C) Springer Science+Business Media, LLC 2011

Included in this issue of Surgical Endoscopy is a touching tribute to a father by his surgeon-son that captures the essence of James F. Lind, Sr., M.D. as a leader, scientist, academic surgeon, and father. How many surgeons have been able to find such a balance in their lives that results in accolades from both family and colleagues?

I first got to know Jim in the 1970s when he and a group of general and colorectal surgeons began discussing the need for an organization that would eventually become the Society of American Gastrointestinal and Endoscopic Surgeons (SAGES). At that time, gastrointestinal endoscopes were diagnostic instruments used almost exclusively by gastroenterologists. Surgical gynecologists and urologists had already incorporated diagnostic and some rudimentary therapeutic endoscopy into their practices. Our group of surgeon-leaders saw the tremendous potential to perform not just biopsies and polypectomies, but major surgical procedures, using endoscopic instrumentation years before the first laparoscopic cholecystectomy. We believed that there was a critical need for a national surgical organization to protect surgeons from the threatened exclusion from the use of these instruments, to support surgeons who wanted to incorporate endoscopy into their practices, to educate them in endoscopic diagnostic and therapeutic procedures, and to foster research in and the further development of minimal access surgery. We were reluctant to create yet another surgical society, but it became evident after preliminary discussions with most of the then-existing surgical organizations (e.g., the Society for Surgery of the Alimentary Tract, the American Society

T. L. Dent $(\bowtie)$

Chair Emeritus, Department of Surgery, Abington Memorial Hospital, 505 Owen Road, Santa Barbara, CA 93108, USA e-mail: tldent@cox.net for Colon and Rectal Surgery, the American College of Surgeons), that few seemed to realize the great potential of endoscopy to surgery, and none were willing to take up our cause and risk the wrath of organized gastroenterology. Thus, SAGES was founded in 1981.

From the start it was obvious to all of us that Jim had the qualities vital to the success of our fledgling organization. With his dry sense of humor and expert management skills, he knew intuitively how to achieve consensus. He had a self-effacing manner, not caring who got the credit for good ideas. He was the no-nonsense, "nuts and bolts" guy who kept our young Society on track, recruited new members, and helped keep the ranks in order. He spent many long hours honing the Society's constitution and served as membership chairman in the days when we still kept membership records on $3^{\prime \prime} \times 5^{\prime \prime}$ cards. Appropriately, Jim's leadership abilities were recognized by his election to our Society's presidency in 1985.

In 1981, the original SAGES board consisted of 17 members: nine colorectal surgeons and eight general surgeons, including Jim. The first SAGES scientific meeting was held in Philadelphia in 1984 in conjunction with Thomas Jefferson University Hospital for 75 enthusiastic attendees. Our first freestanding meeting was in Williamsburg, VA, in 1986, with a budget of $\$ 50,000$ and 110 attendees. Thirty years later, SAGES' membership now exceeds 6,000, our annual budget is several million dollars, our annual meeting attendance exceeds 2,500, and SAGES is recognized internationally as providing the most extensive hands-on endoscopic and laparoscopic educational conferences. After his retirement, Jim enjoyed seeing the annual budget as we grew, and was amazed and thrilled the first time it exceeded $\$ 1$ million. Among its many accomplishments, SAGES has created a foundation for the advancement of minimal access surgery, whose funding 
has almost reached its $\$ 10$ million goal, and helped to establish The Fellowship Council that accredits and administers the annual trainee match for all minimal access surgical fellowships in the United States.

Today, it is estimated that most cholecystectomies, hernia repairs, and appendectomies are being performed using laparoscopic techniques, and advanced endoscopic procedures are being added constantly to the minimal access arsenal. It is because of courageous and visionary surgeons like Jim Lind that SAGES protected endoscopy for surgeons, facilitated the minimal access revolution, and continues to provide the training and education in advanced minimal access procedures to thousands of surgeons for the benefit of their patients. SAGES and I miss Jim, but his legacy remains as strong for the Society he helped create as it does for his son, Scott.

Disclosures Dr. Dent has no conflicts of interest or financial ties to disclose. 